\title{
Avaliação das Práticas de Higienização por Estudantes de Medicina da Universidade Federal da Bahia (Brasil) durante Atendimento Clínico
}

\author{
Assessment of Hygiene Practices Employed \\ by Medical Students at the Federal University \\ of Bahia (Brazil) during Clinical Service
}

\author{
Marcella Santana-Caires ${ }^{I}$ \\ José Tavares-Neto ${ }^{I}$ \\ Paula Amaral-Muniz \\ Valdemiro Silva-Filho \\ Andréa Canário de Santana
}

\section{PALAVRAS-CHAVE \\ - Desinfecção das Mãos; \\ - Assepsia; \\ - Infecção Hospitalar; \\ - Educação Médica.}

\section{KEYWORDS}

- Hand Disinfection;

- Asepsis;

- Cross Infection;

- Medical Education.

\section{RESUMO}

A adesão às normas de higienização é um aspecto importante na prática clínico-hospitalar dos profissionais de saúde. Este estudo avaliou a conduta de 160 estudantes de Medicina do Internato da Faculdade de Medicina da Bahia, da Universidade Federal da Bahia, por meio de um questionário com 22 questões objetivas. Dos 160 questionários incluídos na pesquisa, 76\% dos entrevistados autoavaliaram seu conhecimento sobre as normas de higienização como "excelente" e "bom"; contudo, apenas $50 \%$ realizam a higienização das mãos antes e após contato com o paciente. Cerca de 55\% não concordam com a criação de um novo componente curricular específico para essa temática. As características demográficas da amostra foram diferentes quanto ao sexo em relação a outros estudos, prevalecendo no presente estudo o sexo masculino e faixa etária de 20 a 40 anos. Observam-se resultados divergentes quanto ao conhecimento dos estudantes sobre as normas de higiene e à sua conduta na prática médica. Alguns fatores que levam à não adesão à técnica asséptica pelos estudantes são a abordagem teórica sobre higienização e biossegurança em período diferente do da prática, falta de fiscalização, carência de insumos e materiais, e má conduta de alguns profissionais de saúde.

\section{ABSTRACT}

Adherence to hygiene standards is an important aspect of health professionals' clinical and hospital practice. In this study, we evaluated the behavior of 160 students completing a medical internship at the Faculty of Medicine of Bahia of the Federal University of Bahia, by means of a questionnaire containing 22 objective questions. Of the 160 participants in the survey, 76\% assessed their own knowledge of hygiene standards as "excellent" or "good"; however only 50\% performed hand hygiene before and after patient contact. Around 55\% did not agree with the suggestion of creating a new specific curricular component on the theme. The demographic characteristics of the sample varied in gender in terms of other studies, with a prevalence of male students and an age range of 20-40. We observed divergent results regarding the students' knowledge of the hygiene standards and their conduct thereof in medical practice. Several factors leading to the students' failure to undertake aseptic practice are the fact that the theory of Hygiene and Biosafety is taught at a different time to its practice, as well as the lack of supervision, lack of supplies and materials and misconduct on the part of some health professionals. 


\section{INTRODUÇÃO}

A Portaria no 2.616/1998 do Ministério da Saúde define infecção hospitalar como aquela que é adquirida após admissão do paciente e que se manifesta durante a internação ou após a alta, estando relacionada com o internamento ou com os procedimentos hospitalares realizados. Contudo, a prevenção e o controle das infecções nosocomiais ainda estão entre os problemas que mais crescem no Brasil, ocasionando gastos exorbitantes, pois o valor despendido em pacientes com infecção é cerca de três vezes maior em relação aos pacientes sem infecção ${ }^{1,2}$.

A maioria das infecções hospitalares se deve à resistência dos microrganismos aos antimicrobianos, como ocorre, por exemplo, com o $S$. aureus e o $S$. Epidermidis, resistentes à oxacilina/meticilina; o Enterococcus spp., resistente à vancomicina; as Enterobacteriaceae, resistentes às cefalosporinas de terceira geração; a $P$. aeruginosa, resistente aos carbapenêmicos. Esses registros são extremamente comuns em Unidades de Terapia Intensiva (UTIs) e estão relacionados a inúmeros fatores, tais como presença de pacientes em estado grave; duração prolongada de internamento; excesso de procedimentos invasivos realizados; e maior uso de antimicrobianos ${ }^{3,4}$.

A técnica asséptica pode ser classificada como cirúrgica ou clínica e tem por objetivo o controle e a prevenção de infecção por meio da criação de ambiente estéril ou asséptico (sem germes). Na cirúrgica, o emprego dessa técnica visa à não propagação de microrganismos na ferida cirúrgica ou instrumental cirúrgico estéril; já a assepsia ambulatorial/hospitalar aborda medidas para reduzir a disseminação de patógenos de uma pessoa para outra, sendo utilizada em qualquer atividade/procedimento com risco de exposição. Assim, assepsia seria o conjunto de medidas empregadas para manter a antissepsia e, consequentemente, impedir a contaminação de utensílios ou colonização/infecção das pessoas, ao passo que a antissepsia consiste no uso de agentes químicos, antissépticos, para eliminar microrganismos ${ }^{5}$.

O contato das mãos é uma das principais formas de transmissão de microrganismos de uma pessoa para outra. Dados mundiais indicam que de 2 a 3 milhões de mortes em todo o mundo têm como agente causal a diarreia, facilmente prevenível com a antissepsia das mãos ${ }^{6,7}$. Além disso, o uso de adornos (anéis, pulseiras, relógios, etc.) durante a higienização das mãos oferece maior risco na manutenção nas mãos de bacilos Gram negativos e S. aureus, patógenos comuns em infecções nosocomiais ${ }^{7,8}$.

Outro dado importante, demonstrado por Breathnach et al. ${ }^{9}$, é a alta concentração do patógeno $S$. Aureus encontrada nos estetoscópios não desinfectados após o contato com o paciente, o que torna esse instrumento tão útil na prática clínica um possível vetor de infecção. Esse patógeno também foi en- contrado em jalecos de estudantes de Medicina, principalmente nas áreas de bolso e mangas ${ }^{10}$.

A presença da Comissão de Controle de Infecção Hospitalar $(\mathrm{CCIH})$ permitiu aos hospitais maior controle e prevenção de infecções nosocomiais. Esse órgão promove a supervisão técnica dos procedimentos e a manutenção dos dispositivos utilizados, a busca ativa e a análise dos prontuários de cada paciente.

Atualmente, diversos programas para treinamento e conscientização sobre padrões de higienização surgem como forma de aumentar a adesão, porém as taxas de aderência não ultrapassam $40 \%$, o que reflete a falta de conhecimento dos estudantes sobre a temática. No futuro, esse desconhecimento se somará ao tempo reduzido para o adequado atendimento e à carência de materiais no local de trabalho, e irá repercutir no aumento das taxas de infecção nosocomial ${ }^{11}$. Apesar disso, as condutas de biossegurança no ambiente clínico-hospitalar ainda são pouco debatidas nas universidades de saúde do Brasil, especialmente no Estado da Bahia. Por esse motivo, este estudo objetiva avaliar a conduta e o conhecimento dos estudantes de Medicina do quinto e sexto anos da Faculdade de Medicina da Universidade Federal da Bahia, os quais já frequentam estágios permanentes, que usam as técnicas de assepsia e antissepsia tanto para as mãos quanto para os instrumentos de rotina, na prática clínica, cirúrgica e obstétrica.

\section{METODOLOGIA}

A abordagem deste estudo é do tipo transversal, realizada com estudantes de Medicina dos semestres letivos correspondentes aos quinto e sexto anos do curso (que ingressaram em 2010.1, 2009.2, 2009.1 e 2008.2), da Faculdade de Medicina da Bahia (FMB) da Universidade Federal da Bahia (UFBA), na cidade de Salvador, Estado da Bahia (Brasil).

Os dados foram coletados nas unidades da FMB-UFBA ou nos campos de prática clínica dos estudantes da UFBA (Complexo Hospitalar Universitário Professor Edgard Santos, Ambulatório Magalhães Netto e Maternidade Climério de Oliveira), no período de fevereiro a maio de 2014.

No período deste estudo, um total de 286 estudantes (internos) estavam regularmente matriculados no período letivo de 2014.1 e correspondiam aos ingressos de 2010.1, 2009.2, 2009.1 e 2008.2, em ordem crescente, ou seja, $9^{\circ}, 10^{\circ}, 11^{\circ}$ e $12^{\circ}$. Com base na literatura ${ }^{12}$, foi estimada em $15 \%(p=0,15)$ a probabilidade daqueles com boas práticas de higienização das mãos durante atividades de atendimento clínico, sendo também estimado que a variação desse percentual fosse de $5 \%$ $(\mathrm{d}=0,05)$, para o Intervalo de Confiança de $95 \%$. Com base nesses indicadores, pelo cálculo de Fisher e Yates (1963), o tamanho amostral mínimo foi calculado em 133 estudantes. 
Todos os questionários devidamente completados, com resposta única para cada questão, sem deixar questões em branco (marcou mais de uma alternativa para a mesma pergunta ou deixou alguma questão em branco) foram incluídos na pesquisa.

O questionário utilizado continha 22 questões objetivas, cada uma com cinco opções, diferenciadas pelas letras de "a" a " $\mathrm{e}$ ". Os temas contemplados foram: cumprimento da técnica antisséptica durante o atendimento clínico; impressão pessoal sobre os equipamentos e insumos necessários ao processo de higienização; e alternativas para o aprimoramento dos alunos acerca da técnica antisséptica.

Preliminarmente, para validação interna do questionário, foi realizado estudo piloto com dez estudantes do curso de Medicina de outros semestres do curso médico. A depender da questão, o escore (peso ou pontuação) de cada alternativa da questão variou de -3 a +5 , em que menos 3 (-3) indica a pior conduta possível e mais $5(+5)$ representa a melhor conduta possível.

Os dados foram registrados em planilha do software Excel® e analisados pelo software estatístico Statistical Package for the Social Sciences (SPSS, versão 17.0). Após análise da distribuição descritiva de cada variável, os dados não contínuos foram analisados pelo método do qui-quadrado (\&\#967;2), sem ou com correção de Yates (aplicado quando na tabela 2 × 2 um dos números esperados foi $<5)$, e a probabilidade $(95 \%)$ estimada conforme o número de graus de liberdade (g.1). Quando indicado, para os dados não contínuos e discretos, foi também aplicado o teste não paramétrico de Mann-Whitney ou de Kruskal-Wallis.

Para dados contínuos com distribuição normal, foi utilizado teste $t$ de Student ou Anova, sendo a estimativa do número de graus de liberdade baseada no teste $\mathrm{F}$ das varianças, dependendo se as amostras eram heterocedásticas ( $p<0,05)$ ou homocedásticas ( $\mathrm{p}>0,05)$. Também foi aplicado o teste de correlação de Pearson, com pressuposto de distribuição normal para o conjunto de duas variáveis deste estudo. Nesses testes estatísticos, os resultados foram considerados estatisticamente significantes se a probabilidade (p) do erro tipo I ou alfa (\&\#945;) foi \&\#8804;5\% (p\&\#8804;0,05).

Inicialmente, o projeto deste estudo foi submetido à Plataforma Brasil da Comissão Nacional de Ética em Pesquisa (Conep)/Conselho Nacional de Saúde/Ministério da Saúde e direcionado à análise do Comitê de Ética em Pesquisa (CEP) da Faculdade de Medicina da Bahia da Universidade Federal da Bahia, que o aprovou em 10 de dezembro de 2013 (Parecer CEP-FMB-UFBA nº 487.341/2013), em consonância com a Resolução nº 466/2012 do Conselho Nacional de Saúde/Ministério da Saúde.
Todos os participantes deste estudo foram informados de que se trata de trabalho científico e que os dados obtidos serão publicados observando o sigilo de suas identidades. Só participaram da pesquisa estudantes que estavam de acordo com a proposta do estudo e assinaram o Termo de Consentimento Livre e Esclarecido (TCLE), após a leitura do mesmo.

\section{RESULTADOS}

No período de janeiro a maio de 2014, este estudo foi apresentado a 286 estudantes da FMB-UFBA dos quatro últimos semestres do curso médico que ingressaram nos anos de 2008 (segundo semestre), 2009 (primeiro e segundo semestres) e 2010 (primeiro semestre). Entre esses, 164 (54,5\%) estudantes do programa de internato aceitaram participar do estudo, mas $4(2,4 \%)$ posteriormente foram excluídos porque não informaram sexo, idade e semestre do curso médico. O Quadro 1 mostra a distribuição dessas variáveis demográficas dos 160 estudantes incluídos neste estudo. Os outros estudantes não incluídos $(n=122)$ estavam em outros estágios do programa de internato em outros campos de prática, não próprios da UFBA ( $\mathrm{n}=111$ ); participavam de programa de intercâmbio (n $=3)$; ou eram dessemestralizados $(n=8)$

Como mostra o Quadro 1, em três das quatro turmas a maioria dos estudantes voluntários foi do sexo masculino, sendo no conjunto $63,1 \%(n=101)$ homens e $36,9 \%(=59)$ mulheres, e esta diferença ficou próxima do limite de significância estatística $(\mathrm{p}=0,06)$.

Também como indica o Quadro 1, as idades desses estudantes variaram de 21 a 40 anos, sendo a moda, a mediana e a média ( \pm D.P.), respectivamente, 24 anos; 24 anos; e 24,9 ( \pm $3,0)$. Não obstante, nas quatro turmas houve tendência de os homens terem maior idade, mas sem alcançar significado estatístico; todavia, no conjunto das turmas, a média das idades dos homens $(25,3 \pm 3,3)$ foi estatisticamente superior (teste $\mathrm{T}$ de Student $=2,41 ; \mathrm{p}<0,02 ; \mathrm{g} .1 .=156,90$ ) àquela observada nas mulheres $(24,3 \pm 2,1)$.

A análise pelo teste não paramétrico de Mann-Whitney, a distribuição da idade versus mulheres (\&\#9792;) e homens (\&\#9794;) em cada turma, teve média de postos (mean rank) estatisticamente semelhante: 2010.1, p > 0,15 (\&\#9792; 27,24 vs. \&\#9794; 33,61); 2009.2, p > 0,57 (\&\#9792; 14,63 vs. \&\#9794; 16,50); 2009.1, p > 0,39 (\&\#9792; 14,00 vs. \&\#9794; 17,33); e 2008.1, p > 0,71 (\&\#9792; 17,90 vs. \&\#9794; 19,41), bem como quando essa mesma análise foi feita com o conjunto dos internos incluídos neste estudo, independentemente da turma: mulheres com mean rank de 72,45, e nos homens, de 85,20 (p $>0,79$ ). A representação gráfica destes achados foi registrada no Gráfico 1. 


\section{Quadro 1}

Distribuição do sexo e da idade dos estudantes segundo o semestre do programa de internato (FMB-UFBA)

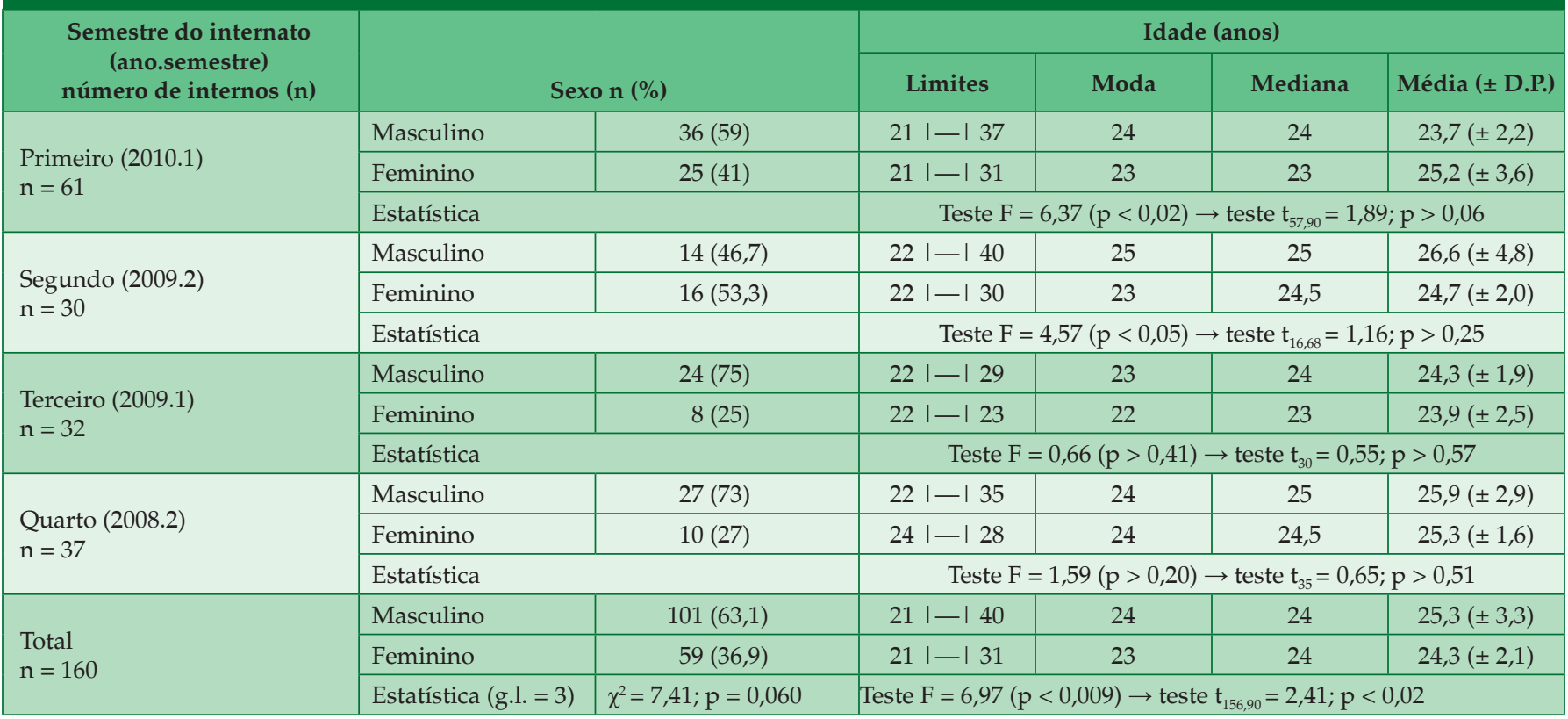

\section{GrÁfico 1}

Idade e sexo dos estudantes conforme semestre letivo

\section{Semestre}

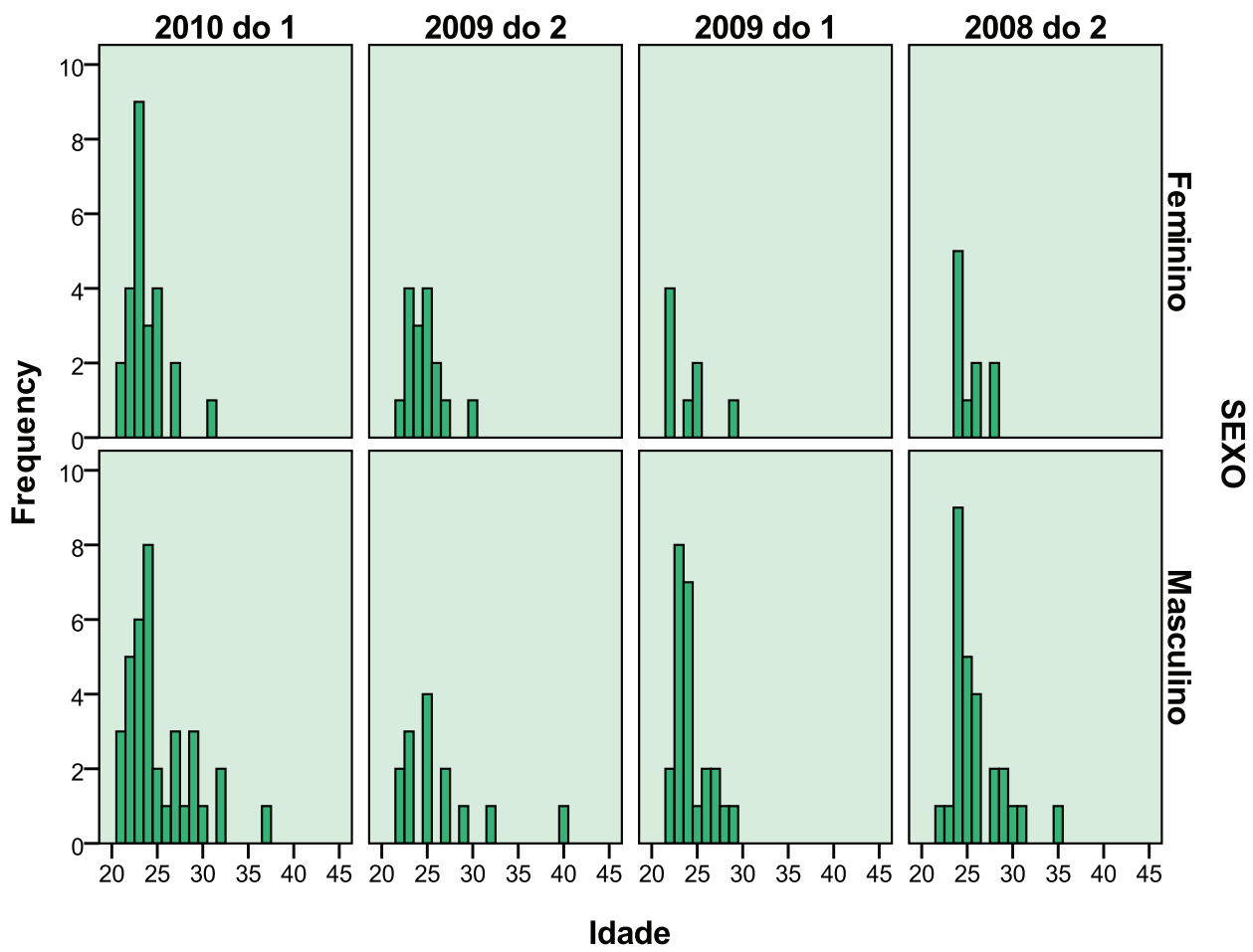


Do primeiro (2010.1) ao quarto (2008.2) semestre do programa de internato do curso médico, era esperado aumento progressivo da idade dos estudantes (Tabela 1); não obstante, os resultados se mostraram semelhantes às idades dos estudantes nesses quatro semestres $(p>0,09)$.

\begin{tabular}{|c|c|c|c|}
\hline \multicolumn{4}{|c|}{$\begin{array}{c}\text { TABELA } 1 \\
\text { Distribuição da idade dos estudantes } \\
\text { versus semestre letivo }\end{array}$} \\
\hline \multirow{2}{*}{$\begin{array}{l}\text { Semestre do internato } \\
\quad \text { (ano.semestre) } \\
\text { - número de Internos (n) }\end{array}$} & \multicolumn{3}{|c|}{ Idade (em anos) } \\
\hline & Moda & Mediana & Média (D.P.) \\
\hline Primeiro $(2010.1)-n=61$ & 23 & 24 & $24,6( \pm 3,2)$ \\
\hline Segundo $(2009.2)-n=30$ & 25 & 25 & $25,4( \pm 3,6)$ \\
\hline Terceiro (2009.1) - n=32 & 23 & 24 & $24,2( \pm 2,0)$ \\
\hline Quarto (2008.2) - n=37 & 24 & 25 & $25,8( \pm 2,6)$ \\
\hline $\begin{array}{l}\text { Total } \\
\mathrm{n}=160\end{array}$ & 24 & 24 & $24,9( \pm 3,0)$ \\
\hline
\end{tabular}

Anova: $F=2,16 ; p>0,09$

Mesmo com esses resultados, mas considerando a falta consistente de homogeneidade entre as quatro turmas, nas análises seguintes os estudantes serão grupados nas duas faixas etárias (21 |-| 24; e $25|-|$ 40), mostradas na Tabela 2, a qual também evidencia serem estatisticamente semelhantes (\&\#967; $2=0,65 ; \mathrm{p}>0,40$ ) em ambos os sexos.

No Quadro 2, foram distribuídas as 15 variáveis relacionadas às práticas de higienização dos estudantes de Medicina (do programa de internato). O somatório dos escores (pesos ou pontuações) das categorias dessas variáveis tem como limites possíveis valores de $-32|-|+33$.

\begin{tabular}{|cccc}
\hline \multicolumn{4}{c}{ TABELA 2} \\
Faixas etárias e sexo dos estudantes \\
incluídos neste estudo \\
\cline { 1 - 2 } $\begin{array}{c}\text { Faixa etária } \\
\text { (anos) }\end{array}$ & \multicolumn{2}{c}{ Sexo $-\mathbf{n}(\%)$} & Total \\
\cline { 2 - 3 } 21 |-| 24 & $55(54,5)$ & $36(61)$ & $91(56,9)$ \\
\hline 25 |-| 40 & $46(45,5)$ & $23(39)$ & $69(43,1)$ \\
\hline Total & $101(100)$ & $59(100)$ & $160(100)$ \\
\hline
\end{tabular}

$\chi^{2}=0,65 ; p>0,40$

\begin{tabular}{|c|c|c|c|c|}
\hline \multicolumn{5}{|c|}{$\begin{array}{c}\text { QUADRO } 2 \\
\text { Distribuição das variáveis estudadas e respectivos } \\
\text { códigos aplicados para as alternativas às respostas } \\
\text { dos } 160 \text { estudantes incluídos neste estudo }\end{array}$} \\
\hline Variável & Sistematização & Peso & $\begin{array}{c}\quad \mathrm{N}^{\circ} \text { de } \\
\text { estudantes }\end{array}$ & $\%$ \\
\hline \multirow{6}{*}{$\begin{array}{l}\text { Frequência da } \\
\text { lavagem das mãos } \\
\text { durante o dia de } \\
\text { atendimento clínico }\end{array}$} & Nunca & -1 & 1 & 0,6 \\
\hline & Não respondeu & 0 & 1 & 0,6 \\
\hline & De 1 a 2 vezes por dia & 1 & 15 & 9,4 \\
\hline & De 3 a 5 vezes por dia & 2 & 29 & 18,1 \\
\hline & $\begin{array}{l}\text { Após contato com o } \\
\text { paciente }\end{array}$ & 3 & 34 & 21,3 \\
\hline & $\begin{array}{l}\text { Antes e depois de } \\
\text { contato com paciente }\end{array}$ & 4 & 80 & 50 \\
\hline \multirow{6}{*}{$\begin{array}{l}\text { Frequência diária } \\
\text { da desinfecção } \\
\text { da campânula do } \\
\text { estetoscópio }\end{array}$} & Nunca & -1 & 58 & 36,2 \\
\hline & Não respondeu & 0 & 2 & 1,3 \\
\hline & De 1 a 2 vezes por dia & 1 & 53 & 33,1 \\
\hline & De 3 a 5 vezes por dia & 2 & 8 & 5 \\
\hline & $\begin{array}{l}\text { Após cada contato com } \\
\text { o paciente }\end{array}$ & 3 & 37 & 23,1 \\
\hline & $\begin{array}{l}\text { Antes e depois de cada } \\
\text { contato com paciente }\end{array}$ & 4 & 2 & 1,3 \\
\hline \multirow{6}{*}{$\begin{array}{l}\text { Frequência da } \\
\text { lavagem das mãos } \\
\text { antes e depois da } \\
\text { coleta de sangue }\end{array}$} & Nunca & -1 & 1 & 0,6 \\
\hline & Não respondeu & 0 & 39 & 24,4 \\
\hline & $\begin{array}{l}\begin{array}{l}\text { Só se houver acidente } \\
\text { por agulha }\end{array} \\
\end{array}$ & 1 & 1 & 0,6 \\
\hline & $\begin{array}{l}\text { Não necessário, porque } \\
\text { uso luvas }\end{array}$ & 2 & 8 & 5 \\
\hline & $\begin{array}{l}\text { Após contato com o } \\
\text { paciente }\end{array}$ & 3 & 22 & 13,8 \\
\hline & $\begin{array}{l}\text { Antes e depois do } \\
\text { contato com o paciente }\end{array}$ & 4 & 89 & 55,6 \\
\hline \multirow{5}{*}{$\begin{array}{l}\text { Frequência do uso } \\
\text { de luvas para coleta } \\
\text { de sangue }\end{array}$} & Nunca & -2 & 0 & - \\
\hline & Raramente & -1 & 0 & - \\
\hline & $\begin{array}{l}\text { Não lembrou ou não } \\
\text { respondeu }\end{array}$ & 0 & 37 & 23,1 \\
\hline & Às vezes & 1 & 0 & - \\
\hline & Sempre & 2 & 123 & 76,9 \\
\hline \multirow{5}{*}{$\begin{array}{l}\text { Frequência com que } \\
\text { reencapa agulha }\end{array}$} & Sempre & -3 & 45 & 28,1 \\
\hline & Às vezes & -2 & 34 & 21,2 \\
\hline & Raramente & -1 & 11 & 6,9 \\
\hline & \begin{tabular}{|l|}
$\begin{array}{l}\text { Não lembrou ou não } \\
\text { respondeu }\end{array}$ \\
\end{tabular} & 0 & 20 & 12,5 \\
\hline & Nunca & 1 & 50 & 31,3 \\
\hline \multirow{5}{*}{$\begin{array}{l}\text { Frequência de troca } \\
\text { de jaleco }\end{array}$} & Muito raramente & -2 & 5 & 3,1 \\
\hline & $\begin{array}{l}\text { Às vezes, } 1 \text { a } 2 \text { vezes } \\
\text { por mês }\end{array}$ & -1 & 21 & 13,2 \\
\hline & \begin{tabular}{|l|}
$\begin{array}{l}\text { Não lembrou ou não } \\
\text { respondeu }\end{array}$ \\
\end{tabular} & 0 & 4 & 2,5 \\
\hline & \begin{tabular}{|l|} 
Regularmente, 1 a 2 \\
vezes por semana \\
\end{tabular} & 1 & 117 & 73,1 \\
\hline & Todos os dias & 2 & 13 & 8,1 \\
\hline \multirow{5}{*}{$\begin{array}{l}\text { Uso de jaleco } \\
\text { durante lanche e/ou } \\
\text { refeição }\end{array}$} & Sempre & -2 & 10 & 6,2 \\
\hline & Às vezes & -1 & 46 & 28,8 \\
\hline & \begin{tabular}{|l|}
$\begin{array}{l}\text { Não lembrou ou não } \\
\text { respondeu }\end{array}$ \\
\end{tabular} & 0 & 0 & - \\
\hline & Só quando está limpo & 1 & 2 & 1,2 \\
\hline & Nunca usa & 2 & 102 & 63,8 \\
\hline
\end{tabular}




\section{Quadro 2}

Distribuição das variáveis estudadas e respectivos códigos aplicados para as alternativas às respostas dos 160 estudantes incluídos neste estudo

\begin{tabular}{|c|c|c|c|c|}
\hline Variável & Sistematização & Peso & $\begin{array}{c}\mathrm{N}^{\circ} \text { de } \\
\text { estudantes }\end{array}$ & $\%$ \\
\hline \multirow{5}{*}{$\begin{array}{l}\text { Frequência de saída } \\
\text { do centro cirúrgico } \\
\text { com roupa de uso } \\
\text { interno ao mesmo }\end{array}$} & Sempre & -3 & 15 & 9,4 \\
\hline & Às vezes & -2 & 42 & 26,2 \\
\hline & Raramente & -1 & 24 & 15 \\
\hline & $\begin{array}{l}\text { Não lembro ou não } \\
\text { respondeu }\end{array}$ & 0 & 22 & 13,8 \\
\hline & $\begin{array}{l}\text { Nunca uso fora do } \\
\text { centro cirúrgico }\end{array}$ & 1 & 57 & 35,6 \\
\hline \multirow{5}{*}{$\begin{array}{l}\text { Quando da } \\
\text { higienização das } \\
\text { suas mãos, usa } \\
\text { pulseiras, anéis e/ou } \\
\text { relógio }\end{array}$} & Sempre & -3 & 33 & 20,6 \\
\hline & Às vezes & -2 & 48 & 30 \\
\hline & Raramente & -1 & 14 & 8,7 \\
\hline & $\begin{array}{l}\text { Não lembrou ou não } \\
\text { respondeu }\end{array}$ & 0 & 3 & 1,9 \\
\hline & Nunca & 1 & 62 & 38,8 \\
\hline \multirow{5}{*}{$\begin{array}{l}\text { Costuma sentar no } \\
\text { leito do paciente } \\
\text { durante atendimento }\end{array}$} & Sempre & -3 & 1 & 0,6 \\
\hline & Às vezes & -2 & 10 & 6,2 \\
\hline & Raramente & -1 & 18 & 11,3 \\
\hline & $\begin{array}{l}\text { Não lembrou ou não } \\
\text { respondeu }\end{array}$ & 0 & 5 & 3,1 \\
\hline & Nunca & 1 & 126 & 78,8 \\
\hline \multirow{5}{*}{$\begin{array}{l}\text { Na enfermaria, } \\
\text { costuma } \\
\text { cumprimentar seu } \\
\text { paciente com o } \\
\text { "aperto de mãos" }\end{array}$} & Sempre & -3 & 75 & 46,9 \\
\hline & Às vezes & -2 & 71 & 44,4 \\
\hline & Raramente & -1 & 9 & 5,6 \\
\hline & $\begin{array}{l}\text { Não lembrou ou não } \\
\text { respondeu }\end{array}$ & 0 & 3 & 1,9 \\
\hline & Nunca & 1 & 2 & 1,2 \\
\hline \multirow{5}{*}{$\begin{array}{l}\text { Quando está doente, } \\
\text { costuma manter } \\
\text { atendimento na } \\
\text { enfermaria ou } \\
\text { ambulatório }\end{array}$} & Sempre & -3 & 17 & 10,6 \\
\hline & Às vezes & -2 & 61 & 38,1 \\
\hline & Raramente & -1 & 36 & 22,5 \\
\hline & $\begin{array}{l}\text { Não lembrou ou não } \\
\text { respondeu }\end{array}$ & 0 & 17 & 10,7 \\
\hline & Nunca & 1 & 29 & 18,1 \\
\hline \multirow{5}{*}{$\begin{array}{l}\text { Costuma esquecer } \\
\text { a higienização das } \\
\text { suas mãos }\end{array}$} & Sempre & -3 & 0 & - \\
\hline & Às vezes & -2 & 64 & 40 \\
\hline & Raramente & -1 & 73 & 45,6 \\
\hline & $\begin{array}{l}\text { Não lembrou ou não } \\
\text { respondeu }\end{array}$ & 0 & 6 & 3,8 \\
\hline & Nunca & 1 & 17 & 10,6 \\
\hline \multirow{5}{*}{$\begin{array}{l}\text { Com qual frequência } \\
\text { costuma higienizar } \\
\text { seu estetoscópio }\end{array}$} & Nunca & -1 & 19 & 11,9 \\
\hline & $\begin{array}{l}\text { Não lembrou ou não } \\
\text { respondeu }\end{array}$ & 0 & 5 & 3,1 \\
\hline & Raramente & 1 & 35 & 21,9 \\
\hline & Às vezes & 2 & 81 & 50,6 \\
\hline & Sempre & 3 & 20 & 12,5 \\
\hline \multirow{7}{*}{$\begin{array}{l}\text { Situações avaliadas } \\
\text { como indispensáveis } \\
\text { para higienização } \\
\text { das mãos }\end{array}$} & $\begin{array}{l}\text { Não lembrou ou não } \\
\text { respondeu }\end{array}$ & -1 & 4 & 2,5 \\
\hline & Após uso de luvas (a) & 0 & 0 & - \\
\hline & $\begin{array}{l}\text { Após utilizar banheiro } \\
\text { ou vaso sanitário (b) }\end{array}$ & 1 & 14 & 8,8 \\
\hline & $\begin{array}{l}\text { No início do turno de } \\
\text { atividades no hospital } \\
\text { (c) }\end{array}$ & 2 & 2 & 1,2 \\
\hline & $\begin{array}{l}\text { Antes e após cada } \\
\text { atendimento clínico (d) }\end{array}$ & 3 & 48 & 30 \\
\hline & $\begin{array}{l}\text { Se alternativas "a", "b", } \\
\text { "c" e "d" }\end{array}$ & 4 & 64 & 40 \\
\hline & $\begin{array}{l}\text { Se alternativas "b", "c" } \\
\text { e "d" }\end{array}$ & 5 & 28 & 17,5 \\
\hline
\end{tabular}

Porém, o somatório (\&\#931;) do valor da pontuação de cada estudante teve limites de $-10|-|+28$, com moda e mediana de 8 pontos. A Tabela 3 mostra a distribuição dessa pontuação em escala intervalar, destacando que só 12 (7,5\%) estudantes tiveram pontuação acima de $50 \%$ do total esperado de pontos $(\mathrm{n}=+33)$, ou seja, \&\#8805;17 pontos; enquanto $10 \%$ $(\mathrm{n}=16)$ tiveram pontuação igual a zero ou menor; e quase a metade $(43,1 \% ; n=69)$ teve pontuação inferior $(<8)$ ao valor da mediana.

\section{TABELA 3}

Pontuação alcançada pelo somatório dos pesos (escores) das 15 variáveis descritas na Tabela 2 deste estudo, a qual corresponde à variável práticas de higienização

\begin{tabular}{lcc}
\multicolumn{1}{c}{$\begin{array}{c}\sum_{\text {da pontuação }} \\
\text {-10 |-| } 0\end{array}$} & $\begin{array}{c}\mathbf{N}^{\text {o }} \\
\text { de casos }\end{array}$ & $\%$ \\
$1|-| 5$ & 16 & 10 \\
$6|-| 10$ & 34 & 21,3 \\
$11|-| 15$ & 57 & 35,6 \\
$\geq 16$ & 37 & 23,1 \\
Total & 16 & 10 \\
\hline
\end{tabular}

As pontuações das práticas de higienização dos estudantes não diferiram estatisticamente nas duas faixas etárias estudadas $(p>0,63)$ e entre aqueles dos quatro semestres letivos ( $p$ $>0,57$ ) (Tabela 4). Esta mesma tabela mostra que os escores das mulheres foram estatisticamente maiores $(\mathrm{p}<0,02)$, do que os observados nos homens.

\section{TABELA 4}

Distribuição das práticas de higienização dos estudantes conforme sexo, faixa etária e semestre do curso médico

\begin{tabular}{|llrcc}
\multicolumn{1}{c}{ Variável } & Distribuição & $\mathbf{N}$ & $\begin{array}{c}\text { Média de } \\
\text { postos }^{(a)}\end{array}$ & Estatística \\
\hline Sexo & Masculino & 101 & 73,76 & $\mathrm{Z}=2,41^{(\mathrm{b})}$ \\
& Feminino & 59 & 92,04 & $\mathrm{p}<0,02$ \\
\hline Faixa etária (anos) & $\leq 24$ & 91 & 79,05 & $\mathrm{Z}=0,46^{(\mathrm{b})}$ \\
& $>24$ & 69 & 82,41 & $\mathrm{p}>0,63$ \\
Semestre letivo & 2010.1 & 61 & 79,85 & \\
(por ano de ingresso. & 2009.2 & 30 & 90,67 & $\chi^{2}=1,95^{(\mathrm{c})}$ \\
semestre) & 2009.1 & 32 & 75,97 & $\mathrm{p}>0,57$ \\
& 2008.2 & 37 & 77,24 & $(\mathrm{~g} .1 .=3)$
\end{tabular}

(a) mean rank de teste não paramétrico; ${ }^{(b)}$ teste de Mann-Whitney; ${ }^{(c)}$ teste de KruskalWallis.

Por isso, também, as pontuações das práticas de higienização dos estudantes foram estudadas em cada estrato 


\section{GrÁfico 2}

Representação gráfica dos dados descritos na Tabela 8

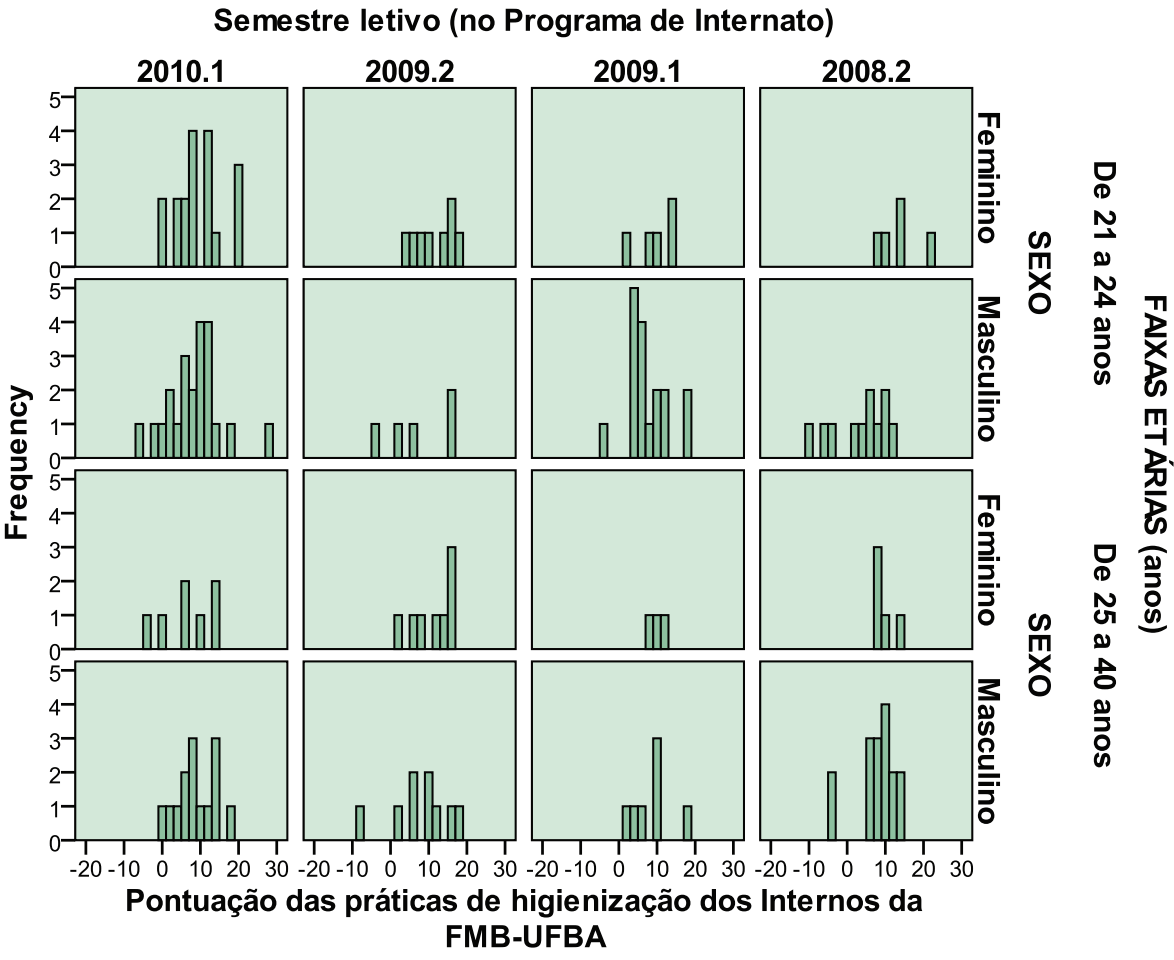

dos mesmos, de acordo com sexo, faixa etária e semestre do programa de internato - no total de 16 estratos (Tabela 5). A análise desse conjunto, pelo teste de Kruskal-Wallis, mostrou não haver diferença estatisticamente significante entre os 16 estratos (\&\#967;2 = 14,70; p>0,46; g.l. = 15). Esses achados são também mostrados no Gráfico 2.

Os $23(14,4 \%)$ estudantes com relatos de maior adesão à lavagem das mãos foram comparados com seus colegas sem igual adesão ( $n=137 ; 85,6 \%$ ), e esses últimos justificaram as seguintes razões para não adesão à lavagem de mãos: (a) falta de recursos materiais no hospital-escola $(\mathrm{n}=96 ; 70,1 \%)$; (b) lavabos em locais inadequados ( $\mathrm{n}=19$; 13,9\%); (c) falta de tempo ( $\mathrm{n}=11 ; 8 \%$ ); (d) falta de conhecimento da necessidade dessa prática $(n=2 ; 1,5 \%) ; 9$ (6,5\%) estudantes anularam todas as alternativas anteriores e não manuscreveram nenhuma outra justificativa. Esses casos ( $n=137)$, pelo teste de Mann-Whitney, tiveram mean rank (média de postos) de 77,28 pela pontuação das práticas relacionadas à higienização, enquanto naqueles $(n=23)$ com adesão à lavagem das mãos essa média foi de 99,70 pontos, sendo essa diferença, como esperado, estatisticamente significante $(Z=$ $2,15 ; \mathrm{p}<0,04)$.

\begin{tabular}{|c|c|c|c|c|}
\hline \multicolumn{5}{|c|}{ TABELA 5} \\
\hline \multicolumn{5}{|c|}{$\begin{array}{l}\text { Pontuação das práticas de higienização nos } 16 \text { estratos } \\
\text { possíveis entre os estudantes avaliados, de acordo com o } \\
\text { semestre no programa de internato, sexo e faixa etária }\end{array}$} \\
\hline Semestre & Sexo & $\begin{array}{l}\text { Faixa etária } \\
\quad(\text { anos) }\end{array}$ & $\begin{array}{l}\mathrm{N}^{\circ} \text { de } \\
\text { casos }\end{array}$ & $\begin{array}{l}\text { Médias de } \\
\text { postos } \\
\text { (mean rank) }^{(a)}\end{array}$ \\
\hline \multirow{4}{*}{ 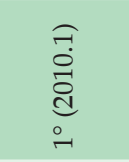 } & \multirow{2}{*}{ Masculino } & $\leq 24$ & 22 & 76,93 \\
\hline & & $>24$ & 14 & 82,86 \\
\hline & \multirow{2}{*}{ Feminino } & $\leq 24$ & 18 & 85,39 \\
\hline & & $>24$ & 7 & 68,79 \\
\hline \multirow{4}{*}{ 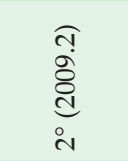 } & \multirow{2}{*}{ Masculino } & $\leq 24$ & 5 & 71,70 \\
\hline & & $>24$ & 9 & 81,22 \\
\hline & \multirow{2}{*}{ Feminino } & $\leq 24$ & 8 & 102,00 \\
\hline & & $>24$ & 8 & 101,81 \\
\hline \multirow{4}{*}{ 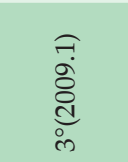 } & \multirow{2}{*}{ Masculino } & $\leq 24$ & 17 & 68,88 \\
\hline & & $>24$ & 7 & 74,79 \\
\hline & \multirow{2}{*}{ Feminino } & $\leq 24$ & 5 & 94,00 \\
\hline & & $>24$ & 3 & 88,83 \\
\hline \multirow{4}{*}{ 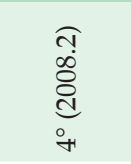 } & \multirow{2}{*}{ Masculino } & $\leq 24$ & 11 & 50,00 \\
\hline & & $>24$ & 16 & 78,94 \\
\hline & \multirow{2}{*}{ Feminino } & $\leq 24$ & 5 & 119,70 \\
\hline & & $>24$ & 5 & 89,30 \\
\hline
\end{tabular}

(a) mean rank do teste não paramétrico de Kruskal-Wallis 
Na Tabela 6, a pontuação das práticas de higienização dos estudantes foi dividida em duas categorias, a serem aplicadas nas análises seguintes, conforme o valor da mediana: $<8$ e $\& \# 8805 ; 8$ pontos, respectivamente com $69(43,1 \%)$ e 91 (56,9\%) estudantes. A distribuição segundo a mediana foi semelhante quanto a sexo $(p>0,06)$, faixa etária $(p>0,36)$ e semestre $(p$ $>0,81$.

\begin{tabular}{|c|c|c|c|c|}
\hline \multicolumn{5}{|c|}{$\begin{array}{c}\text { TABELA } 6 \\
\text { Pontuação das práticas de higienização, } \\
\text { distribuída pela mediana, conforme as } \\
\text { variáveis demográficas dos estudantes }\end{array}$} \\
\hline \multirow{2}{*}{\multicolumn{2}{|c|}{ Variáveis demográficas }} & \multicolumn{2}{|c|}{$\begin{array}{c}\text { Mediana da pontuação das } \\
\text { práticas }-\mathrm{n}(\%)\end{array}$} & \multirow[t]{2}{*}{ Estatística } \\
\hline & & $<8$ & $\geq 8$ & \\
\hline \multirow{3}{*}{ Sexo } & Masculino & $49(71)$ & $52(57,1)$ & \multirow{3}{*}{$\begin{array}{l}\chi^{2}=3,24 \\
p>0,06\end{array}$} \\
\hline & Feminino & 20 (29) & $39(42,9)$ & \\
\hline & Total & $69(100)$ & $91(100)$ & \\
\hline \multirow{3}{*}{$\begin{array}{l}\text { Faixa etária } \\
\text { (anos) }\end{array}$} & $\leq 24$ & $42(60,9)$ & $49(53,8)$ & \multirow{3}{*}{$\begin{array}{l}\chi^{2}=0,79 \\
p>0,36\end{array}$} \\
\hline & $>24$ & $27(39,1)$ & $42(46,2)$ & \\
\hline & Total & $69(100)$ & $91(100)$ & \\
\hline \multirow{5}{*}{$\begin{array}{l}\text { Semestre } \\
\text { letivo }\end{array}$} & 2010.1 & $28(40,6)$ & $33(36,3)$ & \multirow{5}{*}{$\begin{aligned} \chi^{2} & =0,92 \\
p & >0,81 \\
\text { (g.l. } & =3 \text { ) }\end{aligned}$} \\
\hline & 2009.2 & $12(17,4)$ & $18(19,8)$ & \\
\hline & 2009.1 & $15(21,7)$ & $17(18,7)$ & \\
\hline & 2008.2 & $14(20,3)$ & $23(25,2)$ & \\
\hline & Total & 69 & $91(100)$ & \\
\hline
\end{tabular}

O Quadro 3 lista as distribuições observadas nas quatro variáveis associadas ao conhecimento dos estudantes relacionado às práticas de higienização e biossegurança, sendo o somatório (\&\#931;) dessas com variação possível entre -6 |-| +12 pontos; mas a variação encontrada foi de $-1|-|+12$, com moda e mediana de 8 pontos. A maioria $(\mathrm{n}=96 ; 60 \%)$ alcançou pontuação \&\#8805;8 pontos, e, entre esses, 13 (13,5\%) tiveram $11(n=7)$ e 12 pontos $(n=6)$.

A correlação dessa pontuação (conhecimento) com aquela das práticas associadas às práticas de higienização foi estatisticamente significante $(\mathrm{p}<0,001)$ pelo teste de Pearson $(\mathrm{r}=0,26)$; porém, quando essa análise foi por sexo, a correlação com significado estatístico só foi observada nos homens $(\mathrm{r}=0,29 ; \mathrm{p}<0,004)$, e semelhante às mulheres $(\mathrm{r}=0,187 ; \mathrm{p}$ $>0,14)$. Essa associação do conjunto de casos é mostrada no Gráfico 3, do aumento da pontuação das práticas de higienização proporcional ao aumento da pontuação relacionada ao conhecimento dessas práticas pelos estudantes (internos) de Medicina.

\section{Quadro 3}

Variáveis incluídas na estimativa relacionada ao conhecimento das práticas de higiene e biossegurança

\begin{tabular}{|c|c|c|c|c|}
\hline Variável & Sistematização & Peso & $\begin{array}{l}\quad \text { № de } \\
\text { estudantes }\end{array}$ & $\%$ \\
\hline \multirow{5}{*}{$\begin{array}{l}\text { Como avalia seu } \\
\text { conhecimento } \\
\text { sobre normas } \\
\text { de higiene e de } \\
\text { biossegurança }\end{array}$} & Insuficiente & -1 & 2 & 1,2 \\
\hline & Não respondeu & 0 & 1 & 0,6 \\
\hline & Regular & 1 & 35 & 21,9 \\
\hline & Bom & 2 & 98 & 61,3 \\
\hline & Excelente & 3 & 24 & 15 \\
\hline \multirow{6}{*}{$\begin{array}{l}\text { Como } \\
\text { classifica seu } \\
\text { conhecimento } \\
\text { sobre essas } \\
\text { normas em seu } \\
\text { hospital-escola }\end{array}$} & Insuficiente & -1 & 17 & 10,6 \\
\hline & $\begin{array}{l}\text { Não lembra ou não } \\
\text { respondeu }\end{array}$ & 0 & 1 & 0,6 \\
\hline & Regular & 1 & 36 & 22,5 \\
\hline & Bom & 2 & 45 & 28,2 \\
\hline & Muito bom & 3 & 53 & 33,1 \\
\hline & Excelente & 4 & 8 & 5 \\
\hline \multirow{5}{*}{$\begin{array}{l}\text { Qual a } \\
\text { relevância da } \\
\text { leitura das } \\
\text { diretrizes de } \\
\text { higiene }\end{array}$} & $\begin{array}{l}\text { Não ou não considera } \\
\text { assunto relevante }\end{array}$ & -3 & 2 & 1,3 \\
\hline & $\begin{array}{l}\text { Não tenho tempo para esse } \\
\text { tipo de leitura }\end{array}$ & -2 & 17 & 10,6 \\
\hline & Não sei onde encontrar & -1 & 29 & 18,1 \\
\hline & Não respondeu & 0 & 1 & 0,6 \\
\hline & Sim & 1 & 111 & 69,4 \\
\hline \multirow{6}{*}{$\begin{array}{l}\text { Em qual } \\
\text { momento da } \\
\text { graduação } \\
\text { ocorreu contato } \\
\text { com normas de } \\
\text { higiene }\end{array}$} & Nunca ocorreu & -1 & 2 & 1,3 \\
\hline & Não respondeu & 0 & 1 & 0,6 \\
\hline & $\begin{array}{l}\text { Com profissional de saúde no } \\
\text { ambiente hospitalar }\end{array}$ & 1 & 3 & 1,9 \\
\hline & $\begin{array}{l}\text { No início do programa de } \\
\text { internato }\end{array}$ & 2 & 13 & 8,1 \\
\hline & $\begin{array}{l}\text { Por iniciativa própria, } \\
\text { por meio de leituras e/ou } \\
\text { videoaulas }\end{array}$ & 3 & 1 & 0,6 \\
\hline & $\begin{array}{l}\text { Em disciplinas do currículo } \\
\text { médico, antes do internato }\end{array}$ & 4 & 140 & 87,5 \\
\hline
\end{tabular}

Tanto o grupo com maior pontuação nas práticas de higienização e aquele com menor pontuação e também aqueles com maior ou menor conhecimento têm avaliações semelhantes, respectivamente $p>0,11$ e $p>0,91$, quanto à frequência com que encontram materiais para higiene das mãos e dos instrumentos de trabalho no hospital-escola (Tabela 7). No entanto, quando os 23 estudantes com maior adesão à lavagem das mãos foram comparados aos 137 sem adesão (3 excluídos)*, a frequência dos que sempre encontram os materiais para higiene das mãos/instrumentos foi, respectivamente, $34,8 \%(\mathrm{n}=8)$ e $14,6 \%(n=20)$, e essa diferença foi estatisticamente significante (\&\#967; 2 = 4,25 - com correção de Yates; $\mathrm{p}<0,04$ - g.l. = 1 ; neste teste, as categorias "raramente" e "algumas vezes" foram somadas, para evitar maior número esperado $<5$ ). 


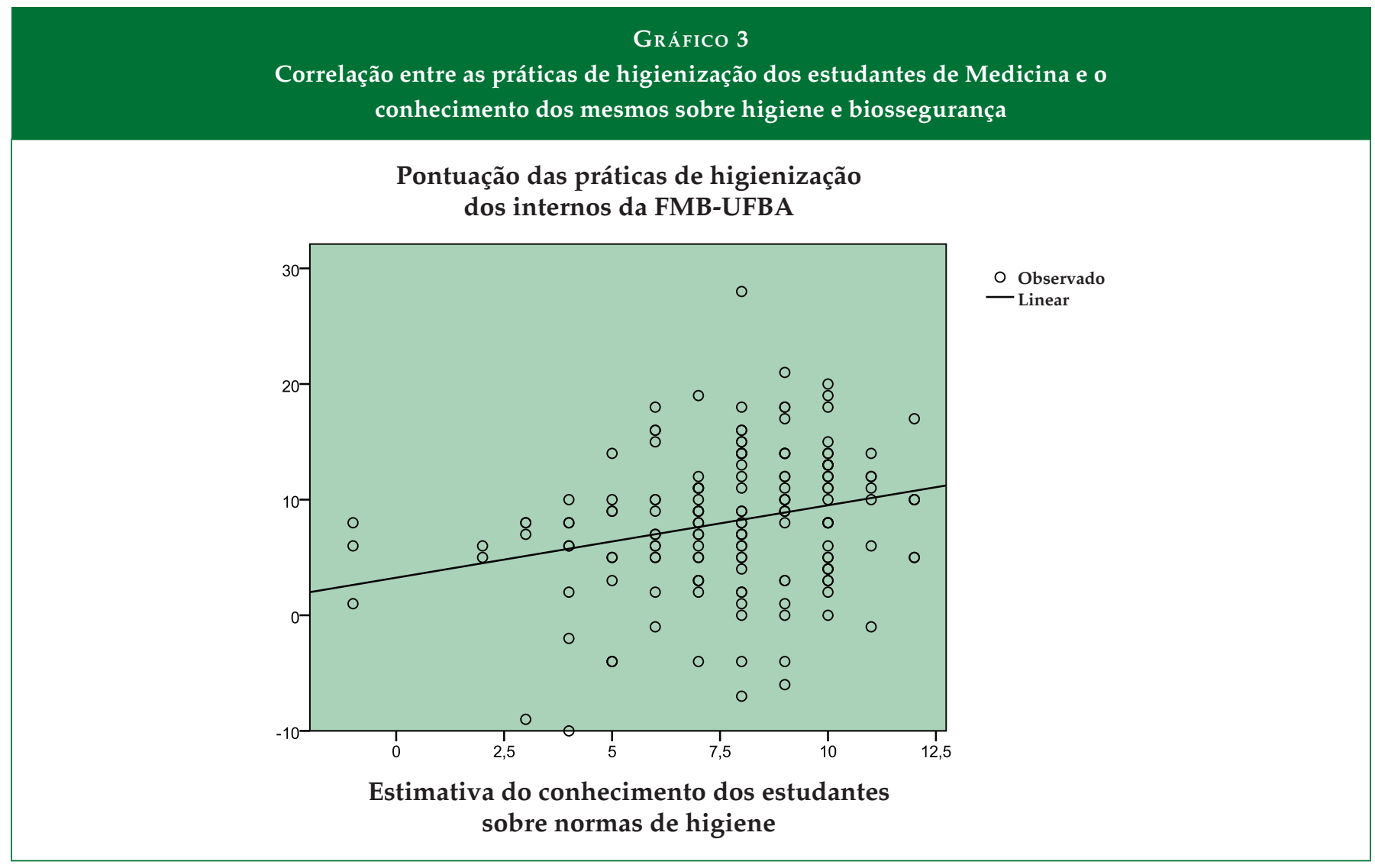

\begin{tabular}{|c|c|c|c|c|c|c|}
\hline \multicolumn{7}{|c|}{$\begin{array}{l}\text { TABELA } 7 \\
\text { Distribuição dos relatos dos estudantes de encontro de materiais para higienização de mãos e } \\
\text { equipamentos versus pontuação para as práticas de higienização e conhecimento dos mesmos }\end{array}$} \\
\hline \multicolumn{2}{|c|}{ Distribuição pela mediana } & \multicolumn{4}{|c|}{ Disponibilidade de materiais no hospital-escola - n (\%) } & \multirow{2}{*}{ Estatística } \\
\hline Variável & Mediana & Raramente & Algumas vezes & Sempre & Total $^{(*)}$ & \\
\hline \multirow{2}{*}{ Práticas de higienização } & $<8$ & $16(23,9)$ & $38(56,7)$ & $13(19,4)$ & $67(100)$ & \multirow{2}{*}{$\begin{array}{l}\chi^{2}=4,15 \\
(\mathrm{p}>0,11) \\
\text { g.1. }=2\end{array}$} \\
\hline & $\geq 8$ & $13(14,5)$ & $65(72,2)$ & $12(13,3)$ & $90(100)$ & \\
\hline \multirow{2}{*}{ Conhecimento das normas } & $<8$ & $12(19,7)$ & $40(65,6)$ & $9(14,7)$ & $61(100)$ & \multirow{2}{*}{$\begin{array}{c}\chi^{2}=0,16 \\
(p>0,91) \\
\text { g.l. }=2\end{array}$} \\
\hline & $\geq 8$ & $17(17,7)$ & $63(65,6)$ & $16(16,7)$ & $96(100)$ & \\
\hline
\end{tabular}

(*) Três estudantes foram excluídos porque não responderam a essa questão.

Quanto à avaliação pelos estudantes da sugestão de criação de componente curricular, obrigatório, com conteúdos concernentes às normas de higiene e de biossegurança, a maioria ( $n=88 ; 55 \%)$ opinou que esses "conteúdos devem ser incluídos em disciplina ou matéria já existente" no currículo médico da FMB-UFBA. Na Tabela 8, essa e outras sugestões dos estudantes foram associadas à pontuação obtida por eles nas questões descritas no Quadro 3: conhecimento das normas de higiene e de biossegurança. Todavia, a análise estatística (Tabela 8) apresentou frequências semelhantes versus pontuação do grau de conhecimento (Teste de Kruskal-Wallis) ou por meio da mediana $(<8$ vs. \&\#8805;8) pelo teste do qui-quadrado. 


\begin{tabular}{|c|c|c|c|c|}
\hline \multicolumn{5}{|c|}{$\begin{array}{c}\text { TABELA } 8 \\
\text { Considerações dos estudantes quanto à propriedade da inclusão de componente curricular sobre } \\
\text { normas de higiene e biossegurança versus conhecimento dos mesmos sobre esse tema }\end{array}$} \\
\hline \multirow{3}{*}{$\begin{array}{c}\text { Criação de componente curricular, obrigatório, com conteúdos concernentes as } \\
\text { normas de higiene e de biossegurança }\end{array}$} & \multicolumn{4}{|c|}{ Pontuação da estimativa de conhecimento } \\
\hline & \multicolumn{2}{|c|}{ Teste de Kruskal-Wallis } & \multicolumn{2}{|c|}{ Mediana - n (\%) } \\
\hline & $\mathbf{N}$ & $\begin{array}{l}\text { Média de } \\
\text { postos }\end{array}$ & $<8$ & $\geq 8$ \\
\hline - É necessária, para discussão em atividades práticas & 27 & 79,24 & $10(15,6)$ & $17(17,7)$ \\
\hline - Inclusão de conteúdos em matéria já existente & 88 & 84,02 & $35(54,7)$ & $53(55,2)$ \\
\hline - A medida não resolve o problema, que é de adesão às normas & 21 & 77,88 & $7(10,9)$ & $14(14,6)$ \\
\hline - Currículo já é extenso e exaustivo, e, portanto, a sugestão é inoportuna & 13 & 74,38 & $6(9,4)$ & $7(7,3)$ \\
\hline - Não é necessária, se as medidas forem introduzidas durante atividades práticas & 11 & 78,33 & $6(9,4)$ & $5(5,2)$ \\
\hline Total & 160 & - & $64(100)$ & $96(100)$ \\
\hline Estatística & \multicolumn{2}{|c|}{$\begin{array}{c}\chi^{2}=2,45 \\
p>0,77(\text { g.l. }=4)\end{array}$} & \multicolumn{2}{|c|}{$\begin{array}{c}\chi^{2}=1,66 \\
\mathrm{p}>0,78(\mathrm{~g} \cdot 1 .=4)\end{array}$} \\
\hline
\end{tabular}

\section{DISCUSSÃO}

Este estudo incluiu mais da metade (56\%) dos internos da Faculdade de Medicina da Bahia (160/286), em que 21,35\% estavam no nono semestre, $10,5 \%$ no décimo, $11,2 \%$ no $11^{\circ}$ e $12,95 \%$ no $12^{\circ}$, porém a maioria dos estudos semelhantes não faz diferença quanto ao período do estudante ${ }^{12}$.

As características demográficas dos estudantes deste estudo foram diferentes das descritas na literatura quanto ao sexo, havendo prevalência do feminino; entretanto, a distribuição da variável idade foi semelhante aos dados encontrados na literatura, em torno de 20 a $40 \operatorname{anos}^{12,13}$. Nas últimas três décadas, há progressivo aumento do percentual de mulheres na FMB-UFBA $^{14}$, situação inexistente antes dos anos 1960, salvo as raras mulheres estudantes em grande parte do século XIX. Também, várias observações de docentes, não publicadas, dão conta do aumento da idade dos estudantes quando do ingresso no curso médico da FMB-UFBA, especialmente nos primeiros anos do século XXI. Isto provavelmente decorre da necessidade de admissão mais precoce ao mercado de trabalho e também da maior flexibilidade do currículo médico.

Os estudos sobre a higienização das mãos também apresentaram frequência elevada de não adesão (28,1\% neste estudo) à prática ${ }^{8,12}$. Esse dado também foi observado em todos os semestres abordados neste estudo, porém se diferencia de outros resultados encontrados na literatura, em que os participantes pertencentes a semestres mais avançados, consequentemente mais experientes na prática clínica, apresentavam maior adesão à prática de higienização das mãos ${ }^{13,15}$. Contudo, em sua autoavaliação quanto ao conhecimento sobre normas de higiene e de biossegurança, cerca de 76,3\% dos estudantes participantes o classificaram como "excelente" ou "bom", porém $30 \%$ dos estudantes voluntários nunca leram sobre as mesmas ${ }^{12}$.

A principal justificativa dos estudantes voluntários para a não adesão é a escassez de materiais no hospital-escola. Também foram mencionadas como causas de não adesão a ausência de pias próximas ao local de atendimento ao paciente, reações cutâneas nas mãos, falta de tempo e falta de informação científica; ou seja, situações semelhantes às discutidas por Tipple et al. ${ }^{16}$. Dados como este indicam certo atraso em relação a outras unidades de saúde, como, por exemplo, a unidade hospitalar de Nova York ${ }^{17}$, onde $100 \%$ dos ambientes possuíam pia destinada à higienização das mãos, algo muitas vezes não visto até mesmo em unidades básicas de saúde brasileiras, onde até existem os lavabos, mas não há os insumos necessários ou próprios à realização adequada da higienização das mãos.

Aproximadamente $77 \%$ dos estudantes voluntários referem que durante todo período de prática clínica não retiram adornos (anéis, pulseiras e/ou relógios). Este fato também foi observado em estudo realizado com profissionais de saúde ${ }^{18}$, o qual constatou que cerca de $84 \%$ desses profissionais não retiravam seus adornos durante a execução da lavagem de mãos, facilitando, assim, a proliferação de microrganismos e, consequentemente, a propagação destes por parte dos profissionais de saúde que estão em contato direto e contínuo com os pacientes. 
Após a utilização de agulhas, o número de estudantes que as reencapam antes do descarte efetivo foi admitido por quase toda a amostra $(56,2 \%)$ do presente estudo, o que caracteriza grave risco à boa prática em saúde. Dessa forma, o profissional se expõe a maior risco de possíveis infecções ${ }^{4,19}$. Estudo conduzido no hospital-escola da Universidade Federal do Paraná demonstrou que a má prática de reencapar agulhas está em terceiro lugar como atividade de maior risco para infecção; também evidenciou que, durante os acidentes hospitalares, a maioria dos estudantes não utilizava EPI (máscara, óculos e sapato fechado) ${ }^{20}$; dados semelhantes foram observados por Gadzama et al. ${ }^{21}$.

O estetoscópio, um dos principais instrumentos de trabalho na prática médica, é também um potencial vetor de infecção nosocomial no ambiente clínico-hospitalar. Sua desinfecção pode reduzir a concentração de bactérias de $90 \%$ para $35 \%{ }^{22}$. Contudo, a não adesão a essa prática é crescente entre os estudantes de Medicina ${ }^{22}$. Neste estudo, somente 1,3\% (n = 2) dos estudantes afirmaram que realizam a desinfecção do estetoscópio antes e depois do contato com o paciente. Esse dado foi semelhante aos resultados de outros estudos realizados com estudantes ou médicos ${ }^{12}$.

Considerando aqueles que realizaram a desinfecção do estetoscópio, este estudo demonstrou que 24,4\% dos entrevistados fazem esse processo após cada contato com o paciente, porém a maioria $(36,2 \%)$ dos entrevistados nunca fez a limpeza do estetoscópio. Em contraste com esses dados, Herbert et al. ${ }^{12}$ notaram que $42 \%$ realizavam a desinfecção do estetoscópio após cada contato com o paciente e Jones et al. ${ }^{23}$ relataram que apenas $7 \%$ nunca realizaram a limpeza do mesmo. Ao lado desse dado, tem-se que a maioria (89\%) dos estetoscópios com frequência está contaminada por estafilococos ${ }^{23}$, principalmente o $S$. aureus, o que se pode prevenir com a execução de simples desinfecção desse instrumento, em que se reduz em até $97 \%$ a concentração bacteriana ${ }^{9}$. Portanto, em qualquer conteúdo voltado à educação é relevante divulgar e até demonstrar esse fato.

Outro aspecto avaliado no questionário foi o ato de recepcionar os pacientes com um "aperto de mãos". Apenas 1,2\% dos estudantes nunca o realizaram, o que remete a uma característica cultural, mas que não está de acordo com as orientações da OMS, em que se indica a lavagem de mãos antes do contato com o paciente, sendo que esta foi realizada por apenas $50 \%$ dos entrevistados no presente estudo ${ }^{12,24}$. Além disso, o número de estudantes que efetivamente realiza a troca de jalecos diariamente ainda foi bastante reduzido: somente $8,1 \%(n=13)$ o fazem todos os dias, resultado semelhante (5\%) ao encontrado por Herbert et al. ${ }^{12}$. Esse dado é ainda mais significativo quando relacionado com o número de estudantes que em algum mo- mento usa o jaleco em refeitórios, fato indicado por cerca de $64 \%$ dos estudantes neste estudo. Somado a isso, tem-se que o número de estudantes que sai do centro cirúrgico para outras áreas dos hospitais, como enfermarias e refeitórios, vestido com o pijama cirúrgico em algum momento da prática é de $51 \%$ dos entrevistados. Assim, a propagação dessas e de outras atitudes errôneas já mencionadas aponta os profissionais de saúde como os principais vetores da disseminação de patógenos. Além disso, também demonstra uma pirâmide hierárquica em relação a maior vivência clínica, em que os mais experientes, tidos como verdadeiros detentores do conhecimento, são exemplos para os mais novos, o que colabora para a manutenção e propagação desses e de outros erros, pois, como parece óbvio, e isso é mostrado no Gráfico 3, as boas práticas têm relação com o conhecimento teórico aplicado à área de biossegurança.

Os estudantes relataram que tiveram o primeiro contato com a temática sobre higienização em alguma das matérias da grade curricular anterior ao internato. Também afirmaram que esse tema é de extrema importância (69,4\% neste estudo). Entretanto, quando questionados sobre a criação de componente curricular com abordagem específica sobre as normas de higienização, 55\% dos entrevistados concordaram apenas em incluir esses assuntos em matéria já existente, pois consideram a grade curricular extensa.

O presente estudo apresenta a limitação de incluir apenas uma instituição ou curso da área da saúde, e isso impossibilita a comparação. Um estudo dessa natureza talvez tivesse maior consistência se fosse do modelo quali-quantitativo, pois, desse modo, ter-se-iam melhores indicadores daqueles efetivamente aderentes à boa prática da higienização, e esse grupo seria mais bem comparado com o outro sem essa adesão. Assim, outros estudos serão necessários para melhor comparação com outras populações e melhor estabelecimento dos resultados obtidos neste estudo.

\section{CONCLUSÕES}

Há contradição entre o número de estudantes que autoavaliaram o conhecimento sobre normas de higiene e biossegurança como "excelente" e "bom" e os que aderem à técnica asséptica adequadamente.

A introdução ao tema higienização e biossegurança ocorre num período afastado e dissociado da prática clínica, dificultando a adesão efetiva dos estudantes.

\section{REFERÊNCIAS}

1. Brasil. Normas para o Programa de Controle de Infecção Hospitalar. Ministério da Saúde. Portaria nº 2.616 de 12 de maio de 1998. D.O.U., 13 de maio de 1998. 
2. Sousa CMM, Alvez MSCF, Moura MEB, Silva AO. Os direitos dos usuários da saúde em casos de infecção hospitalar. Rev Bras Enferm, 2008; 61: 411-17.

3. Almeida RCC, Kuaye AY, Serrano AM, Almeida PF. Avaliação e controle da qualidade microbiológica de mãos de manipuladores de alimentos. Rev. Saúde pub, 1995; 29: 290-94.

4. Mendonça AP, Fernandes MSC, Azevedo JMR, Silveira WCRS, Souza ACS. Lavagem das mãos: adesão dos profissionais de saúde em uma unidade de terapia intensiva neonatal. Acta Sci Health Sci, 2003; 25: 147-53.

5. Center for Disease Control (CDC). Guideline for hand hygiene in health care settings. Recommendations of the healthcare infection control practices advisory committee and the HICPAC/SHEA/APIC/IDSA Hand Hygiene Task Force. MMWR: Morb. Mortal Wkly Rep, 2005; 51: 1-45.

6. Brasil. Anexo 01: Protocolo para a prática de higiene das mãos em serviços de saúde. Ministério da Saúde. Brasília, 2013.

7. Jumaa, PA. Hand hygiene: simple and complex. Int J InfectDis, 2005; 9: 3-14.

8. Felix CCP, Myadahira AMK. Avaliação da técnica de lavagem das mãos executadas por alunos do Curso de Graduação em Enfermagem. Rev Esc Enferm USP 2009; 43:139-45.

9. Breathnach AS, Jenkins DR, Pedler SJ. Stethoscopes as possible vectors of infection by staphylococci. Brit Med J 1992; 305: 1573-74.

10. Loh W, Ng VV, Holton J. Bacterial flora on the white coats of medical students. J Hosp Infec 2000; 45:65-8.

11. Boyce M, Pittet D. Guidelines for hand hygiene in health-care settings: recommendations of the Healthcare Infection Control Practices Advisory Committee and the HIC-PAC/SHEA/APIC/IDSA Hand Hygiene Task Force, MMWR recommend rep 2002; 18: 786-90.

12. Herbert VG, Schlumm P, Kessler HH, Frings A. Knowledge of and Adherence to Hygiene Guidelines among Medical Students in Austria. Hindawi Publishing Corporation. Interdisciplinary Perspectives on Infectious Diseases, 2013.

13. Graf K, Chaberny F, Vonberg RP. Beliefs about hand hygiene: a survey in medical students in their first clinical year. Am J of Infect Control 2011; 39: 885-88.

14. Tavares-Neto J. Formandos de 1812 a 2008 pela Faculdade de Medicina da Bahia. Contexto/AMeFS: Feira de Santana; 2008. 331 p.

15. Van de Mortel TF, Kermode S, Progano T, Sansoni J. A comparison of the hand hygiene knowledge, beliefs and practices of Italian nursing and medical students. J Adv Nurs 2012; 68: 569-79.
16. Tipple AFV, Medonça KM, Melo MC, Souza ACS, Pereira MS, Santos SLV. Higienização das mãos: o ensino e a prática entre graduandos na área da saúde. Acta Sci Health Sci 2007;29: 107-14.

17. O'Boyle CA, Henly SJ, Larson E. Understanding adherence to hand hygiene recommendations: the theory of planned behavior. Am J Infect Control 2001; 29: 352-60.

18. Scheidt KLS, Carvalho M. Avaliação da prática de lavagem das mãos pelos profissionais de saúde em atividade lúdico-educativas. Rev Enferm UERJ 2006; 14: 221-25.

19. Markovic-Denic L, Brankovic M, Maksimovic N, Jovanovic B, Petrovic I, Simic Marko, Lesic A. Occupational Exposures to Blood and Body Fluids among Health Care Workers at University Hospitals. Srp Arh Celok Lek 2013; 141: 789-93.

20. Reis PGTA, Driessen AL, Costa ACBA, Nasr A, Collaço IA, Tomasich FDS. Perfil epidemiológico de acidentes com material biológico entre estudantes de medicina em um pronto-socorro cirúrgico. Rev Col Bras Cir 2013; 40: 287-92.

21. Gadzama GB, Bawa SB, Ajinoma Z, Saidu MM, Umar AS. Injection safety practices in northeastern Nigeria. Niger J of Clin Pract 2014; 17: 134-39.

22. Saunders C, Hryhorskyj L, Skinner J. Factors influencing stethoscope cleanliness among clinical medical students. J Hosp Infect 2013; 84: 242-44.

23. Jones JS, Hoerle D, Riekse R. Stethoscopes: A Potential Vector of Infection? Ann Emerg Med 1995; 26: 296-99.

24. Organização Mundial de Saúde. WHO Guidelines on Hand Hygiene in Health Care. Geneva: WHO; 2009.

\section{CONTRIBUIÇÃO DOS AUTORES}

José Tavares-Neto: orientador e revisor do trabalho. Paula Amaral-Muniz: confecção do questionário. Valdemiro Silva-Filho: análise dos resultados. Andréa Canário de Santana: aplicação dos questionários.

\section{CONFLITO DE INTERESSES}

Os autores declaram não haver conflito de interesses.

\section{ENDEREÇO PARA CORRESPONDÊNCIA}

Marcella Santana-Caires

Rua Wanderley Pinho, 181, Edf. Grandes Mares, Apt 102

Itaigara - Salvador

CEP 41.815-270 BA

Email: marcella_caires@hotmail.com 